\title{
Dom Samuel Ruiz García em Chiapas: do anticomunismo à Teologia Indígena (1960-1968)
}

\author{
Bishop Samuel Ruiz García in Chiapas: \\ from anticommunism to the Native Theology (1960-1968)
}

Igor Luis Andreo*

RESUMO

Este artigo parte do objetivo de apresentar o papel de conscientização étnico-política desempenhado pela Teologia da Libertação entre comunidades indígenas do estado de Chiapas (México), concentrando-se na tentativa de compreensão das especificidades político-teológicas assumidas pela diocese localizada na cidade de San Cristóbal de las Casas sob o bispado de Samuel Ruiz García que se iniciou em 1960. Para realizar tal tarefa procurou-se acompanhar aspectos do processo de transformações do pensamento sócio-teológico de Samuel Ruiz e também das transformações pelas quais a Igreja católica passou no período - enfocando os setores com os quais Samuel Ruiz manteve relações mais estreitas - com intuito de compreender como o entrelaçamento entre diversos fatores resultou nas opções adotadas pelo bispo de San Cristóbal.

PALAVRAS-CHAVE: Samuel Ruiz García. Anticomunismo. Indigenismo. Teologia da Libertação. Teologia Indígena.

\section{ABSTRACT}

This article aims to present the role of ethnopolitical conscientization played, in the period from 1968 to 1974, by the Liberation Theology among indigenous communities of Chiapas (Mexico), focusing on trying to understand the political-theological specificities assumed by the diocese in the city of San Cristobal de las Casas under the Bishop of Samuel Ruiz García - which began in 1960. To accomplish this task we tried to monitor aspects of the transformation of socio-theological thought of Samuel Ruiz and also the transformations through which the Catholic Church passed in the period - focusing on sectors with which Samuel Ruiz maintained closer relations with the aim of understand how the intertwining of several factors resulted in the options chosen by the bishop of San Cristóbal.

KEY-WORDS: Samuel Ruiz García. Anticommunism. Indigenism. Liberation Theology. Native Theology.
... la evangelización tal como se estaba llevando a cabo en el continente, era simple y llanamente una destrucción de culturas y una acción dominadora.

... Entonces ¿qué cosa era evangelizar?

Dom Samuel Ruiz García

\footnotetext{
* Mestre em História e Sociedade pela Universidade Estadual Paulista (UNESP) - Campus de AssisEmail: igor_andreo@hotmail.com
} 


\section{Introdução}

Este artigo consiste na síntese de uma das reflexões contidas na Dissertação de Mestrado (defendida em fevereiro de 2011) Teologia da Libertação e Cultura Política Maia Chiapaneca: o Congresso Indígena de 1974 e as raízes do Exército Zapatista de Libertação Nacional. Seu objetivo é tentar compreender o caráter peculiar que a Teologia da Libertação, paulatinamente, foi assumindo em território chiapaneco sob o bispado de Samuel Ruiz García, uma vez que se parte da hipótese de que o cristianismo teve grande importância para o processo de (re)valorização étnica, conscientização política e para fomentar o auxílio mútuo entre comunidades das quatro etnias majoritárias em Chiapas.

É importante explicitar que não estamos reduzindo a explicação apenas à figura de Dom Samuel Ruiz, assim diminuindo o protagonismo desempenhado por outros atores. A ênfase que será dada neste artigo a Samuel Ruiz é devida a sua posição ocupada enquanto bispo da diocese de San Cristóbal de las Casas, uma vez que foi a partir de suas escolhas e conseqüentes orientações que se abriram as possibilidades para que os agentes envolvidos com a diocese e, até mesmo, as próprias comunidades indígenas pudessem optar por rumos posteriormente tomados e que não necessariamente foram determinados pela vontade do bispo.

Tampouco atribuímos algum tipo de "genialidade" a Samuel Ruiz. Visamos apenas compreender parte de sua trajetória e algumas características contextuais da Igreja católica do período que abriram um leque de possibilidades específico e influíram para que tomasse determinadas decisões e não outras.

\section{Ambiente e Alicerces da Formação de Samuel Ruiz García}

Em 1960, Samuel Ruiz García foi nomeado bispo da diocese de San Cristóbal. O episcopado é o último grau do sacramento da Ordem Sacerdotal e confere autoridade máxima em jurisdição e magistério no território alcançado pela diocese, cabendo ao bispo a exclusividade de ministrar os sacramentos, conferir ministérios, ordenar presbíteros e diáconos, entre outras atribuições, o 
que se traduz em um grande poder político em potencial, uma vez que religião e política são esferas que se entrelaçam ${ }^{2}$ e a sociedade mexicana (e latinoamericana) desse período era esmagadoramente marcada pelo catolicismo ${ }^{3}$ ainda que em muitíssimos casos sob diversas formas sincréticas:

Quienes le conocen [Samuel Ruiz], afirman que siempre formó parte de una élite intelectual. Su carrera fue meteórica. Con menos de treinta años, el obispo de León, Manuel Martín del Campo y Padilla lo hizo rector del seminario y canónigo. Algo inconcebible en México; León era una diócesis importante, cuna de prelados conservadores. Luego, el Papa Bueno lo consagro obispo [...] (FAZIO, 1994, p. 68).

Nesse período o ideário de Samuel Ruiz era fortemente marcado pelo anticomunismo, como comprova sua primeira carta pastoral, dirigida violentamente contra a Revolução Cubana e lançada logo após assumir a diocese de San Cristóbal:

[...] detrás de una doctrina que toma como bandera la justicia social, el comunismo se fue infiltrando al esgrimir la antigua arma de la falsedad, la hipocresía, el engaño y la calumnia; habiendo logrado que muchos vean la hoz y el martillo como un símbolo de libertad y reivindicación social, sin que perciban el fondo rojo de iniquidades y crímenes sin cuenta con que este destruidor del sistema se ha impuesto donde ha colocado su garra opresora. (RUIZ apud SAINTPIERRE, 2001, p. 65).

O anticomunismo do novo bispo, resultante de sua formação familiar e teológica, ia ao encontro do pensamento imperante no período tanto no Vaticano, como na Igreja mexicana.

Samuel Ruiz García nasceu em três de novembro de 1924, na cidade de Irapuato, no estado de Guanajuato, região centro-oeste do México. Filho de pais católicos fervorosos, o jovem Samuel foi criado em ambiente de perseguição à Igreja, exacerbado justamente a partir de 1924, com a presidência do general Plutarco Elías Calles:

\footnotetext{
${ }^{2}$ Sobre o tema das relações intrínsecas entre religião e política, sugere-se conferir: COUTROT, Aline. Religião e política. In: RÉMOND, René (dir.). Por uma história política. Rio de J aneiro: Editora FGV, 2003. 2a ed. p. 331-363.

${ }^{3} \mathrm{Na}$ década de 1960, 97,5\% dos mexicanos professavam nominalmente o catolicismo.
} 
Calles fue el representante de un grupo de políticos convencidos de que el catolicismo era incompatible con el Estado. Los callistas eran nacionalistas y, para ellos [...] el católico no podía ser un buen ciudadano puesto que su primera lealtad era con Roma. (FAZIO, 1994, p. 16)

Os conflitos entre o Estado e a Igreja católica levaram a um levante popular, a Revolución Cristera ou Cristiada, ${ }^{4}$ cujo palco principal foi a região centro-oeste, ou seja, o local onde vivia a família de Samuel Ruiz. La Cristiada iniciou-se em 1927 e foi encerrada em 1929, quando o Estado, representado pelo presidente Portes Gil, e a Igreja, com a o arcebispo do México Pascual Díaz, entraram em um acordo que colocou fim às hostilidades: "[...] la Iglesia católica había pasado de una situación perseguida (1920-1930) a otra marginada (19301940) [...]" (FAZIO, 1994, p. 26).

Sob esse novo contexto, a partir dos anos 30 foi permitido aos católicos criarem um partido, a Acción Nacional (PAN), e um movimento, a Unión Nacional Sinarquista (UNS), fundada em 1937. O pai de Samuel Ruiz, Maclovio Ruiz, foi um militante ativo do movimento sinarquista.

Segundo Jean Meyer, (1989) o sinarquismo constituía-se como um amálgama entre nacionalismo radical; catolicismo com as mesmas características presentes no movimento integralista brasileiro; e defesa de um corporativismo com caracteres fascistas e apresentado como terceiro caminho entre capitalismo e socialismo. O sinarquismo condenava o nazismo e a deificação do Estado e da raça como heranças do protestantismo, ao mesmo tempo em que demonstrava simpatia pelo general Francisco Franco em razão de sua restauração da tradição católica e da hispanidade.

Nesse período o controle da educação constituía um dos pontos principais do embate entre Estado e Igreja, levando ao fechamento das escolas religiosas. Isto fez com que os pais de Samuel Ruiz não lhe enviassem a um centro de ensino secular, preferindo que ele aprendesse as primeiras letras em casa e, posteriormente, lhe matriculando em colégios católicos particulares, em busca de uma educação "mais refinada". Aos treze anos foi mandado a um seminário na cidade de León de Los Aldama que, devido à vigência de leis anticlericais, funcionava de maneira precária.

\footnotetext{
4 Para maiores detalhes acerca da Revolución Cristera, sugere-se conferir: MEYER, J ean. Estado y sociedad con Calles. México: El Colegio de México, 1981.
} 
Entretanto, a partir de 1940, quando Manuel Ávila Camacho assumiu a presidência do México, as relações entre o Estado e Igreja começam a mudar. Houve uma aproximação entre a alta hierarquia eclesiástica, que buscava recuperar o poder perdido nas décadas anteriores, com o governo federal, que soube utilizar a Igreja como agente de coesão social para consolidar a estrutura política:

\footnotetext{
Así, el gobierno comenzó a tolerar ciertas prácticas religiosas expresamente prohibidas por la Constitución, a cambio de que la Iglesia usara su peso moral sobre los creyentes, a fin de eliminar cualquier conflicto que obstaculizara el desarrollo capitalista (FAZIO, 1994, p. 42).
}

A partir de 1945, o governo federal mexicano adotou uma postura anticomunista, o que possibilitou uma maior convergência ideológica entre Igreja e Estado, uma vez que essa postura governamental ia ao encontro da política adotada pelo Vaticano com o Papa Pio XII, assim tornando-se pedra angular da militância católica mexicana.

E Em 1947, Samuel Ruiz foi estudar com um grupo de seminaristas na Pontifícia Universidade de Roma, graduando-se em Teologia Dogmática e sendo ordenado sacerdote em 1949. Decidiu continuar os estudos em Roma, especializando-se em Sagrada Escritura em 1951 e concluindo seu doutorado em 1952.

Esse período romano de sua formação coincidiu com a ascensão do anticomunismo na Igreja católica sob o pontificado de Pio XII, o Papa que havia condecorado o general Franco e elogiado os esforços dos fascistas italianos no combate contra o ateísmo materialista. Em 1947, Pio XII convocou os militantes da Ação Católica e afirmou que a situação implicava em optar "por ou contra Cristo", isto é, a posição oficial da Igreja romana passou a ser de que ou se era anticomunista ou se estava contra Cristo e Igreja. (FAZIO, 1994, p. 40)

Após concluir os estudos em Roma, Samuel Ruiz regressou ao seminário de León - nos anos 1950 uma cidade caracterizada por um forte acento conservador - onde começou a lecionar Teologia e Sagrada Escritura, e como era praxe na Igreja mexicana do período, não incidia em assuntos ligados à crítica social. Em pouco tempo foi designado "prefecto de estudios" e, em 1954, com apenas trinta anos, foi nomeado reitor do seminário. Logo após ocorreu 
uma vacância e, assim sendo, Samuel Ruiz foi nomeado cônego, cargo que garantia privilégios, distinção: “[...] Samuel Ruiz supo lucir el boato. Y como sus pares, llevó capa morada, armiño blanco y anillo cuasi episcopal. Parecían cardenales" (FAZIO, 1994, p. 46).

Por outro lado, em 1958 Ángelo Guiseppe Roncalli, um filho de camponeses pobres, tornou-se Papa, adotando o nome de J oão XXIII. Até então a postura do Vaticano havia sido de ferrenha crítica à modernidade, o que levou à perda de inúmeros fiéis, devido ao afastamento cada vez maior entre o ideário transcendente pregado pela Igreja e o mundo que a rodeava. João XXIII assumiu a crise pela qual passava a Igreja e decidiu que o catolicismo deveria renovar-se e adaptar-se à nova realidade, o que o levou a convocar, em 1959 (90 dias após assumir o pontificado), um Concílio Ecumênico Vaticano, que se iniciou em 1962 e será tratado mais adiante.

1959 também é o ano da Revolução Cubana, cujos efeitos dividiram os setores cristãos mexicanos, mas acentuaram o anticomunismo da alta hierarquia eclesiástica, o que coincidia com a linha ideológica adotada sob o sexênio do presidente Gustavo Díaz Ordaz (1964-1970).

Desta forma, ao assumir o episcopado da diocese de San Cristóbal em 1960, Dom Samuel Ruiz era o reflexo da formação familiar e teológica que recebera até então, chegando a utilizar corriqueiramente pelas ruas suas imponentes vestimentas de bispo, em sinal de protesto contra as limitações legais impostas à Igreja. Era o típico bispo de seu tempo e espaço, ou seja, marcadamente anticomunista e ostentador de toda pompa que um elevado cargo eclesiástico podia garantir aqueles que entendiam a Igreja como uma instância superior, acima da sociedade.

\section{Indigenismo e Anticomunismo}

Em seus primeiros passos como bispo, Samuel Ruiz buscou observar as condições dos fiéis atingidos pela diocese. Em San Cristóbal encontrou uma elite ladina, ${ }^{5}$ composta principalmente por criadores de gado, comerciantes, profissionais liberais e políticos. Elite esta que é a “[...] mais tradicional e racista

\footnotetext{
${ }^{5}$ Denominação empregada em Chiapas para designar os mestiços.
} 
do estado, onde até os anos 60 havia toque de recolher para os indígenas" (FIGUEIREDO, 2003, p. 55).

Por outro lado, o que o bispo encontrou nas comunidades indígenas foi miséria e abandono por parte do Estado, mas também da própria Igreja, uma vez que havia apenas 13 padres para todo o território alcançado pela diocese. ${ }^{6}$ Ao constatar essa realidade, Samuel Ruiz elaborou um plano pastoral composto por três aspectos: "[...] enseñar castilla al indígena; ponerles zapatos y mejorar su dieta. Esa era la base humana mínima, necesaria, para poder desarrollar una evangelización" (FAZIO, 1994, p. 57). Estas medidas serviam também como forma de combater o avanço do protestantismo sobre as comunidades indígenas, além do "sorrateiro espectro do comunismo".

As medidas adotadas por Samuel Ruiz não eram algo pioneiro, pelo contrário, eram perfeitamente compatíveis com o assistencialismo paternalista comumente adotado pela Igreja católica e com certas características das políticas indigenistas mexicanas do período.

De acordo com Federico Navarrete, (2004, p. 108) o regime surgido após a Revolução mexicana foi continuador da política liberal nacionalista e da ideologia da mestiçagem, que foram reforçadas ao longo do século XX pelo sistema educacional e jurídico e pelos meios de comunicação, ao privilegiar e exaltar valores ligados à cultura mestiça, ocidental e "moderna", ao mesmo tempo em que desvalorizavam as culturas supostamente atrasadas dos grupos indígenas. Nesse contexto, a partir da década de 1920, antropólogos conceberam o indigenismo, que consistia em formulações políticas que visavam impor forçosamente a incorporação dos indígenas à identidade nacional mestiça. Paulatinamente, as formulações indigenistas passaram a propor a integração e mestiçagem dos indígenas através da ciência, do "progresso" e do convencimento pacífico. Deste modo, o indigenismo passou a recomendar que fossem realizados estudos profundos das características e necessidades das comunidades indígenas para que, a partir desse conhecimento, o governo implantasse políticas de apoio econômico, educativo e social com intuito de eliminar a miséria e integrar os indígenas à Nação:

${ }^{6}$ Em razão da necessidade de não exceder o espaço reservado a este artigo, não apresentaremos detalhes referentes à dura realidade das comunidades indígenas chiapanecas desse período. 
La idea de estos antropólogos era que los pueblos indígenas, al ver los beneficios que traían consigo el progreso y la ayuda gubernamental aceptarían voluntariamente a la cultura mestiza para así incorporarse al progreso nacional y continuar mejorando su nivel de vida. (NAVARRETE, 2004, p. 108).

A partir da década de 1940, o "Instituto Nacional Indigenista" (INI) colocou em prática esta política:

O indigenismo é um movimento generoso que tratou de redimir os índios, elevando sua forma de vida. Mas interpretou sua 'redenção' como sua integração na cultura nacional dominante, criollo e mestiça, por meio do abandono, conseqüentemente, paulatino, do que constituía sua diferença (VILLORO, 2002. p. 174) ${ }^{7}$

Contudo, apesar dessas limitações, na década de 1960 os membros do INI constituíam o único bastião de combate à situação de exploração dos indígenas imperante em Chiapas. E a partir das relações de Samuel Ruiz com o INI é possível compreender melhor como pensava o bispo recém nomeado. Em 1962, o cronista Fernando Benítez conseguiu uma entrevista com Dom Samuel Ruiz. A seguir destacaremos alguns apontamentos do cronista acerca do bispo e trechos do diálogo entre os dois:

[...] el joven prelado distribuía equitativamente su odio entre un comunismo que él necesitaba "inventar" a diario [...] y un protestantismo contra el cual no podía luchar [...] sus enemigos, en aquél entonces, eran los miembros del Instituto Nacional Indigenista (INI); los únicos que en México de los años sesenta se esforzaban [...] por quebrantar la estructura feudal de Chiapas.

Todos los miembros de la "buena sociedad" de San Cristóbal participaban en aquella cruzada [...]

A la cabeza de la campaña estaba el clero, que acusaba a los funcionarios y maestros del INI de comunistas [...]

[Fernando Benítez] - Hay choques, hay conflictos entre los maestros y algunos miembros de su clero.

[Samuel Ruiz] - [...] ¿Podría usted citarme un caso concreto?

[Fernando Benítez] - Le cito a usted el caso del cura Adolfo Trujillo, dueño de la finca Bojoshac y dueño de esclavos. Aliado a los caciquillos de la región, se opuso a que se construyera la escuela en sus

\footnotetext{
7 Este projeto "integracionista" adotado para as políticas indigenistas mexicanas perdurou até a década de 1970, quando, paulatinamente, foi sendo substituído:

[...] por el "indigenismo de participación", que reconocía el derecho a los indios de decidir sobre su propio desarrollo y de conservar sus formas económicas y sociales vernáculas; pero éste resultó ser un intento oficial de adelantarse a la organización indígena autónoma, que se incubaba, afianzando así la legitimidad del Estado. Se limitó a remozar la política cultural hacia los indígenas (educación bilingüe-bicultural) y se hundió con la crisis financiera del Estado de los ochenta, en la burocracia y en la corrupción [...] (MESTRIES BENQUET, 2001, p. 124).
} 
tierras - una escuela que a él no le costaba un solo centavo - y persiguió con saña al maestro indio. No le importaba la escuela, sino las enseñanzas de la escuela.

[Samuel Ruiz] - Ese es el problema. Desearíamos una enseñanza católica.

[...] - Vivimos una época de conflictos y de crisis. El comunismo representa una fuerza real que debe tenerse en cuenta. Allí tiene ese Fidel Castro...(FAZIO, 1994, p. 59-61).

Contudo, posteriormente ventos advindos de Roma alimentaram correntes tempestuosas do catolicismo latino-americano, que viriam a abalar as certezas conservadoras do jovem bispo.

\section{O Concílio Vaticano II}

Em 1962 ocorreu a primeira sessão do XXI Concílio Ecumênico da Igreja católica, denominado Concílio Vaticano II, cuja última sessão foi realizada em 1965. Samuel Ruiz García foi um dos bispos mexicanos que assistiram às sessões do Concílio Vaticano II. Participou de todas as sessões.

Para muitos autores esse acontecimento pode ser considerado como marco que possibilitou o surgimento da Teologia da Libertação. No entanto, como todo marco histórico, este também é arbitrário e não deve ser generalizado.

Michel Löwy (2000) adota outra cronologia ao apontar que a Teologia da Libertação constitui a materialização intelectual surgida, em princípios da década de 1970, como reflexo e, simultaneamente, como reflexão acerca de um amplo movimento social, que ele denominou como Cristianismo da Libertação, uma vez que o movimento ultrapassava os limites da Igreja. De acordo com esse autor, as origens do Cristianismo da Libertação remontam ao impacto causado pela convergência de fatores internos e externos à Igreja católica, uma vez que, por um lado, com a Revolução Cubana de 1959 ocorreu uma intensificação das lutas sociais na América Latina e uma crise de legitimidade do sistema político e, por outro lado, a partir do término da Segunda Guerra Mundial iniciou-se um processo de desenvolvimento de novas correntes teológicas, novas formas de cristianismo social e uma abertura crescente às preocupações da filosofia moderna e das ciências sociais, que foram legitimadas com a eleição do Papa J oão XXIII, em 1958, e com o Concílio Vaticano II. 
Todavia, Löwy afirma que o processo de radicalização da cultura católica Latino-Americana não começou nos níveis superiores da Igreja, nem tampouco a partir de uma transformação popular da Igreja iniciada de baixo para cima. Surgiu primeiro em movimentos laicos, ativos entre a juventude estudantil e nas comunidades pobres, sobretudo com as comunidades eclesiais de base (CEB) em princípios dos anos 1960. (MURO, 1994). ${ }^{8}$

Nesse contexto ocorreu o Concílio Vaticano II. Antes de tratarmos de seus efeitos sobre Dom Samuel Ruiz, apresentaremos algumas de suas características que consideramos importantes segundo nossos interesses, para que assim se torne possível pensar as especificidades do caso de Chiapas.

A partir das reflexões apresentadas por Roberto Oliveros Maqueo (1990), , é possível apontar como principal característica do Concílio Vaticano II o entendimento da Igreja como estando inserida no mundo objetivo, ao invés de perceber-se e concentrar-se apenas no mundo transcendental. Ademais, o Concílio contribuiu para a superação da dicotomia material/natural versus espiritual/transcendental, uma vez que seus documentos afirmaram que a vocação do homem é somente uma, a divina, não existindo espaço para se entender, por um lado, uma história transcendental e sagrada, e por outro, uma história profana e que carece de valor cristão. Sendo assim, o homem cristão, para seguir sua vocação divina, deve trabalhar em prol da melhora das formas de vida, tanto em sentido espiritual quanto material, o que plantou a semente de reflexões ligadas ao campo do social e político, até então vedadas ao pensamento teológico.

Essas e outras reflexões anunciadas no Concílio Vaticano II possibilitaram o surgimento do Cristianismo da Libertação. Partiremos de duas visões, uma mais interna, mais próxima ao espaço das reflexões teológicas (OLIVEROS MAQUEO, 1990; LIBÂNIO, 2008) e outra externa, referente ao espaço laico das ciências sociais (LÖWY, 2000) - em alguns pontos convergentes, em outros divergentes, contudo majoritariamente

\footnotetext{
8 De acordo com Víctor Gabriel Muro (1994), no âmbito urbano mexicano, desde a década de 1950 havia uma estrutura de movimentos relativamente renovadores organizados pela Ação Católica e pela juventude estudantil, entretanto, estas organizações não alcançavam os espaços rurais.

9 OLIVEROS MAQUEO, Roberto. Historia Breve de la Teología de la Liberación (1962-1990). In: ELLACURÍA, Ignácio ; SOBRINO, J on. (Org.). Mysterium liberationis: conceptos fundamentales de la Teología de la Liberación. Madrid: Trotta, 1990. v. 1, p. 17-50.
} 
complementares - com intuito de compreender os aspectos principais que caracterizaram de um modo geral esse fenômeno plural ocorrido no cristianismo Latino-Americano.

Roberto Oliveros Maqueo dividiu a Teologia da Libertação em quatro períodos: Gestação, de 1962 a 1968; Gênesis, de 1969 a 1971; Crescimento, de 1972 a 1979; e Consolidação, de 1979 a 1987. Apesar de acreditarmos que este tipo de divisão é homogeneizante, ela será adotada por entendermos que seu emprego permite perceber elementos essenciais que predominaram em cada período, assim tornando mais claras as especificidades do caso analisado posteriormente.

O período de Gestação - no qual se concentrarão as análises deste artigo - se iniciou logo após o Concílio Vaticano II, que desde sua convocação em 1959 incitou a reflexão teológica, tendo grande recepção na América Latina, o que levou bispos, teólogos e, sobretudo, segmentos leigos ligados ao catolicismo a refletir sobre os novos apontamentos advindos do Vaticano a partir de sua própria realidade e cultura, o que pode ser apresentado como o principal elemento de origem da Teologia da Libertação, uma vez que a realidade latinoamericana de onde partiram estas novas reflexões teológicas era amplamente marcada por misérias, exploração e marginalização. A nova concepção acerca da vocação divina do cristão incentivava a busca pela transformação destas condições vivenciadas por amplas maiorias latino-americanas, o que era fortemente alimentado pela ebulição social causada pela Revolução Cubana. Isto levou, paulatinamente, à busca dos conhecimentos das ciências sociais, ${ }^{10}$ uma vez que era necessário conhecer as causas dessa situação injusta para poder combatê-la eficazmente.

Neste período duas teorias explicativas foram mais influentes entre os segmentos renovadores da Igreja católica latino-americana: a teoria do desenvolvimento ou desenvolvimentismo e a teoria da dependência. Nos anos seguintes à primeira sessão do Concílio Vaticano II predominou o desenvolvimentismo que, em linhas gerais, constituía-se na interpretação da América Latina como uma região subdesenvolvida, atrasada em relação aos

${ }^{10} \mathrm{O}$ que foi possível graças à grande abertura às ciências em geral (não somente às sociais) permitida pelos apontamentos do Concílio Vaticano II. 
países economicamente ricos, cujo modelo de modernização deveria ser copiado para se alcançar o mesmo desenvolvimento e eliminar a pobreza. ${ }^{11}$

Em razão da história e condições singulares da Igreja católica no México, ${ }^{12}$ foi somente a partir do Concílio Vaticano II que começaram a surgir as primeiras e tímidas divisões no seio da Igreja entre setores considerados renovadores ou progressistas e os tradicionalistas conservadores, uma vez que antes de 1962 as questões debatidas no Concílio não entraram em pauta para a Igreja mexicana, cuja principal preocupação era sua própria organização e manutenção.

Sendo assim, é evidente que as questões colocadas no Concílio, que apareceram como novidades aos olhos de Samuel Ruiz, causaram algum impacto sobre seu entendimento acerca de sua tarefa enquanto bispo: "[...] quizás porque él contaba con una sólida formación científica, gracias a la cual pudo entrar en contacto con las élites intelectuales de obispos y teólogos europeus [...] Y con los latinoamericanos que abrían camino [...]" (FAZIO, 1994, p. 72).

No entanto, as mudanças ocorreram de maneira gradual e, de certo modo, foram superficiais. ${ }^{13} \mathrm{O}$ Concílio não gerou nenhuma grande ruptura na atuação "indigenista" de Dom Samuel Ruiz, mas houve algumas transformações importantes.

11 Essa visão também era compartilhada por algumas correntes marxistas, que defendiam a necessidade de buscar o desenvolvimento tecnológico e industrial seguindo os modelos "burgueses". Entretanto, esta busca era almejada enquanto uma etapa necessária para a criação de uma classe operária consciente e, portanto, revolucionária, uma vez que o desenvolvimento era entendido como condição para aceleração das contradições e, conseqüentemente, dos conflitos entre as relações de produção e as forças produtivas.

12 Maria Ligia Coelho Prado afirma que no final do século XIX e início do século XX o México foi dominado por idéias positivistas e sua ótica materialista, ligada a proposição de ordem social e progresso econômico, o que ia ao encontro dos anseios das elites nacionais, pois possibilitava a imposição da ordem social frente às "inquietas" camadas populares e, concomitantemente, a adoção de um forte anticlericalismo em oposição ao conservadorismo religioso, uma vez que defendia uma posição forçosamente subalterna para a Igreja, apontada como uma instituição retrógrada diante do Estado. A autora ainda afirma que os embates do século XIX entre liberais, defensores do laicismo, e conservadores, ligados à Igreja, deixaram raízes, acentuadas com a Revolução Mexicana (onde a Igreja adotou posicionamentos ultraconservadores), levando o anticlericalismo a assumir proporções profundamente ideológicas e políticas, desta forma tornando peculiar o contexto e a história da Igreja católica mexicana no século XX (PRADO, 1986, p. 29).

13 Todavia, segundo Víctor Gabriel Muro, em outras regiões mexicanas o Concílio impulsionou a formação em áreas rurais de grupos cristãos voltados para a transformação sócio-religiosa, sobretudo no estado de Morelos (conferir mapa 01), onde, em 1967, foi criado pelo bispo Sergio Méndez a primeira CEB mexicana. Estas CEB's consistiam em pequenos grupos onde, através da leitura da Bíblia, refletia-se a respeito dos problemas específicos da comunidade e tentava-se solucioná-los. Estas e outras organizações progressistas foram duramente atacadas pelo episcopado tradicionalista mexicano, que as desarticulou e dissolveu (MURO, 1994, p. 166-167). 
A partir do Concílio, o bispo foi assumindo, paulatinamente, uma postura orientada pelo desenvolvimentismo. Um dos resultados disso foi a manutenção do isolamento frente ao do clero Latino-Americano: “[...] Se sentía que relacionarnos con América del Sur era como querer aprender cómo hacernos desarrollados a partir del subdesarrollo" 14

Além disso, as transformações ocorridas estão relacionadas às orientações do documento regimini Episcoporum, votado ainda na primeira sessão do Concílio, em 1962. Este documento propunha a descentralização da Igreja, o que levou Samuel Ruiz a buscar, logo após seu regresso a Chiapas, a aplicação desta orientação.

Juntamente com os bispos Alfonso Sánches Tinoco, de Papantla (estado de Veracruz), e Adalberto Almeida, de Zacatecas (capital do estado de Zacatecas), Dom Samuel Ruiz criou uma pastoral em conjunto, que enfatizava a pastoral social. A partir de 1964, esta pastoral deu origem a Unión de Mutua Ayuda (UMAE), que em seu ápice, em 1967, chegou a incorporar vinte e cinco dioceses e uma grande equipe de assessores em diversos ramos das ciências sociais. Entretanto, apesar da tendência reformista e da ênfase fornecida à pastoral social, a UMAE era formada por um grupo heterogêneo, o que explica, ao menos parcialmente, a relativa facilidade com que o setor mais tradicionalista do episcopado mexicano logrou o aniquilamento total de sua estrutura em 1971.

Neste contexto, o bispo de Chiapas, paulatinamente, foi recorrendo ao instrumental das ciências sociais - com apoio técnico da UMAE - para melhor conhecer a região onde se localizava a diocese e, até mesmo, a cultura indígena, contudo motivado apenas por preocupações sociais paternalistas orientadas pelo desenvolvimentismo e pelo indigenismo e não a partir de intenções étnicoteológicas.

Outra grande transformação ocorrida refere-se aos catequistas indígenas. Em Chiapas, os primeiros catequistas indígenas foram formados a partir de 1952, pelo bispo Lucio Torreblanco, sobretudo como forma de combater o avanço inicial de algumas denominações protestantes de procedência estadunidense. A formação teológica fornecida a esses indígenas era tradicional

${ }^{14}$ Ruiz García (apud FAZIO, 1994, p. 86). 
e elementar, mas mesmo assim o movimento de catequistas cresceu consideravelmente, principalmente nas zonas tzeltales (VOS, 2002, p. 217-218).

Sob a orientação de Samuel Ruiz a partir de 1962, esse modesto quadro inicial mudou de figura com a criação de duas escolas diocesanas - sob responsabilidade de representantes da ordem marista:

\begin{abstract}
De estas escuelas salieron, entre 1962 y 1968, más de 700 catequistas procedentes de distintas regiones indígenas de Chiapas. Salieron con buena preparación bíblica, dogmática y moral, además de haberse enriquecido con varias habilidades (carpintería, horticultura, sastrería, cocina) y conocimientos (español, matemáticas, higiene, salud) [...] [entretanto]

El método utilizado era muy dinámico, pero occidentalizante y vertical. Padecía también de dos grandes lagunas. En primer lugar, no tomaba en cuenta la cultura de los pueblos a los cuales pertenecían los alumnos, de manera que éstos, al regresar a sus comunidades, solían actuar en contra de las creencias y prácticas antiguas. Por otro lado, tampoco ofrecía respuestas a la situación de opresión en la que vivía el campesinado indígena (VOS, 2001, p. 220).
\end{abstract}

Portanto, sob o impacto do Concílio Vaticano II, Samuel Ruiz reforçou e buscou expandir para outras regiões mexicanas a missão evangelizadora e de melhora da condição de vida dos indígenas, entretanto sob uma perspectiva assistencialista, paternalista, indigenista e desenvolvimentista. Sua preocupação em relação aos indígenas possuía um caráter sócio-econômico, mas não político, o que consistia em uma forma possível de interpretação das orientações do Concílio, apesar de não ser a única. Samuel Ruiz já não percebia a Igreja e seu papel como algo essencialmente transcendente e acima da sociedade, mas seu pensamento ainda era marcadamente anticomunista e indigenista: a saída para a "salvação" dos indígenas era vista como sua "mexicanização", isto é, com a integração do indígena à sociedade capitalista mexicana - que vivia um processo de industrialização - através da assistência social visando o desenvolvimento econômico e da educação (ladina) laica e, sobretudo, religiosa em moldes católicos romanos, ou seja, por meio do abandono paulatino da cultura étnica nativa. 


\section{A Conferência de Medellín e a Incipiente Teologia Indígena}

Em 1966, graças ao impulso produzido pelo Concílio Vaticano II, foi convocada a Segunda Conferência Geral do Episcopado Latino-Americano, realizada entre 26 de agosto e 7 de setembro de 1968, na cidade de Medellín, na Colômbia. Entre 1966 e 1968 houve uma imensa eclosão de declarações, documentos e reuniões realizados como preparativos para a Conferência.

Foi a partir desses preparativos que a teoria da dependência começou, paulatinamente, a se impor como uma alternativa ao desenvolvimentismo, sobretudo através dos especialistas que auxiliavam os bispos. A teoria da dependência, grosso modo, explicava que a situação de pobreza vivenciada na América Latina era fruto da exploração gerada por sua dependência estrutural frente aos países desenvolvidos do sistema capitalista, dependência esta que somente poderia ser extinta com uma transformação estrutural que acabasse com o sistema econômico capitalista em vigência. Inclusive o termo libertação é característico da linguagem empregada pelos autores ligados à teoria da dependência, sofrendo alterações ao ser apropriado pelo discurso cristão, que o desprendeu de sua semântica estritamente política e econômica.

Apesar de ser uma teoria surgida do marxismo, isto não significa que todos que adotaram a teoria da dependência como explicação para a causa da pobreza vivenciada por milhões de latino-americanos, necessariamente, aceitaram outros aspectos e conceitos fundamentais da teoria marxista, como a luta de classes ou a necessidade de uma revolução que instaure um regime socialista. 15

O Papa Paulo VI 16 também foi marcante para a Conferência de Medellín, sobretudo através de suas cartas encíclicas, dente as quais se destacou a

\footnotetext{
15 [...] nessas análises do capitalismo, o horizonte crítico vinha da análise marxista. O uso dessa análise sempre foi uma das questões mais controvertidas da TdL. Nesse ponto, as posições variaram do emprego de algumas poucas categorias marxistas até a adoção da análise marxista de modo mais coerente. A luta de classe era uma das categorias que mais causava polêmica. Pois usava-se a expressão seja simplesmente para denunciar o fato como até para significar uma chave heurística e hermenêutica da história, para ler os acontecimentos passados, presentes e futuros. (LIBÂNIO, 2008, p. 16).

${ }^{16}$ Assumiu como Papa em junho de 1963, após o falecimento de J oão XXIII, dando continuidade às sessões do Concílio Vaticano II e aprovando o tema proposto pelos bispos progressistas da América Latina para a Conferência de Medellín: "A igreja na atual transformação da América Latina à Luz do Concílio". Faleceu em agosto de 1978.
} 
Populorum Progressio, (PAULO IV, 2009) publicada em 1967. Desta carta encíclica nos interessa destacar sucintamente algumas características principais.

O desenvolvimentismo aparece como cerne das reflexões ao longo de todo o documento, contudo ele é lido através de uma lente cristã e a partir do convivio com diversas questões trazidas pelas ciências sociais - inclusive pela teoria da dependência - resultando na defesa de um "desenvolvimento integral", ou seja, tanto das nações "atrasadas", quanto dos indivíduos e, sobretudo, não apenas referente ao desenvolvimento econômico, mas também político, social e espiritual.

Dois pontos foram fundamentais para legitimação das idéias defendidas pelos movimentos ligados ao Cristianismo da Libertação e, conseqüentemente, para o surgimento da Teologia da Libertação: a identificação dos pobres como o alvo principal da missão da Igreja e a afirmação da necessidade de ações sociais e políticas (não partidárias ou ideológicas) da Igreja e dos cristãos.

Assim sendo, as propostas sócio-políticas apresentam-se como a colocação de limites ao capitalismo liberal, isto é, ao livre-mercado, à busca do lucro como fim em si mesmo, à fortuna desmedida e, até mesmo, ao direito de inviolabilidade absoluta da propriedade privada, defendendo que todo direito deveria subordinar-se ao combate ao subdesenvolvimento e à garantia à subsistência e aos instrumentos para o desenvolvimento humano integral.

É possível enquadrar essas propostas como uma terceira via que procurava colocar-se como opção entre, por um lado, um liberalismo sem limites e praticado em uma situação injusta, por ser desigual, entre países desenvolvidos e subdesenvolvidos (aqui o tema da dependência aparece de forma indireta) e, por outro lado, a resposta marxista revolucionária, um "mal" que devia ser evitado.

Desta forma, a busca da solidariedade e caridade universal é apresentada como solução. As transformações são encomendadas como dever a ser cumprido por todos os "homens de bem", sobretudo aos que detém qualquer tipo de poder ou riqueza, sendo um dever humanista e solidário das nações ricas se empenharem em contribuir para que as outras nações progridam e alcancem um elevado nível de desenvolvimento industrial, tecnológico e social, mas garantindo a autonomia soberana e a manutenção das peculiaridades culturais 
próprias dos países em desenvolvimento, ao mesmo tempo em que é cobrado dos indivíduos abastados o trabalho solidário para contribuir com o desenvolvimento material, educacional e espiritual dos mais necessitados.

A Conferência de Medellín encerra o período de Gestação. Apresentaremos alguns dos pontos que consideramos importantes para a análise posterior. Todavia, não se pode esquecer que os documentos finais da Conferência, apesar da busca pelo consenso, são plurais - em decorrência das distintas influências que recaíam sobre a Igreja católica e seus fiéis latinoamericanos.

Fernando Torres-Londoño (2007) aponta dois traços distintivos da Conferência: primeiro, a prioridade dada ao homem latino-americano, que estaria vivenciando um período decisivo de seu processo histórico; segundo, a necessidade de ações urgentes da Igreja para com este momento de transformação da América Latina. Estes são os dois pontos que fornecem unidade, que procuram costurar e conciliar a evidente tensão entre as diferentes posturas presentes nos documentos finais de Medellín.

Roberto Oliveros Maqueo (1990, p. 30) apresenta aquilo que considera como os três temas principais tratados na Conferência de Medellín: o amor ao próximo e a paz em uma situação de violência institucionalizada; os pobres e a justiça; e a unidade da história e a dimensão política da fé.

Os três temas são complementares e juntos fornecem uma idéia das reflexões que levaram ao surgimento da Teologia da Libertação. Acerca do primeiro tema, a conclusão dos conferencistas foi a de que o amor ao próximo e a paz pregados por Cristo estão em contradição com a situação de violência institucionalizada, geradora de injustas desigualdades sociais, sob a qual estão organizadas as sociedades da América Latina.

Com o segundo tema, foi afirmado que pobreza vivenciada pela maioria dos povos latino-americanos é uma injustiça em relação à missão de salvação proposta por Cristo, demandando não apenas conhecimento e denúncia, mas também trabalho com intuito de transformá-la.

Por fim, esse trabalho para a transformação somente pode ser proposto em virtude da retomada das conclusões do Concílio Vaticano II que sustentam o entendimento da unidade da história, isto é, a simultaneidade do temporal e 
espiritual. Isto tornou possível a conclusão de que a ação eclesial deve adentrar no terreno do sócio-político e contribuir para a para a libertação humana no plano histórico, uma vez que ela está relacionada com o reino e os desígnios de Deus.

Entendemos que são diversas as interpretações possíveis acerca da Conferência de Medellín, devido, sobretudo, às margens abertas pelo caráter plural de seus documentos finais. Contudo, acreditamos que o conteúdo da carta encíclica Populorum Progressio predominou como base para a maior parte desses documentos e, por outro lado, as posturas que foram mais assimiladas pela embrionária Teologia da Libertação foram aquelas que enfatizavam a dependência latino-americana e, ao invés de encomendarem a solução dos problemas a ações provenientes da solidariedade dos mais favorecidos, focavam em diversas formas da Igreja contribuir para que os próprios pobres buscassem sua (auto) libertação:

[...] O texto da Conferência encontrou, pois, um amplo contexto de interpretação e aplicação. Ele foi reconhecido como inspiração para a Teologia da Libertação, que se evidencia a partir de 1970, com teólogos que já escreviam antes de Medellín, como J uan Luis Segundo, Gustavo Gutiérrez, Hugo Assmann [...] (TORRES-LONDOÑO, 2007, p. 21).

Desta forma, as posições "progressistas" apresentadas durante a Conferência de Medellín podem ser interpretadas como esboços da vindoura Teologia da Libertação.

Paralelamente ao processo que levou ao surgimento da Teologia da Libertação, ocorriam movimentações entre agentes envolvidos com um pequeno setor eclesiástico, que possuía interesses gerais convergentes com aqueles representados pelo Cristianismo da Libertação, entretanto encontrava-se fortemente vinculado à realidade de diversas comunidades indígenas latinoamericanas. A essa movimentação teológica atribui-se as raízes da Teologia Indígena. ${ }^{17}$ Essa paulatina tomada de consciência por parte do setor

\footnotetext{
${ }^{17}$ É possível encontrar denominações como Teologia Autóctone, Nativa, etc., em substituição ao termo Teologia Indígena ou Índia, o que se justifica com o argumento de que as civilizações pré colombianas possuíam religiões com teologias, sacerdotes, ritos, práticas, etc., altamente elaborados e, com o advento da conquista e colonização, esta teologia originária sofreu um processo de hibridização com a teologia católica, contudo mantendo-se viva e, conseqüentemente, em constante transformação, juntamente com diversos universos culturais indígenas (também
} 
"progressista" da Igreja latino-americana acerca da realidade referente às culturas indígenas é possível de ser percebida através de Conferências e Encontros. ${ }^{18}$

Em abril de 1968, Samuel Ruiz aceitou o convite para participar de um desses eventos: o segundo Encontro patrocinado pelo Departamento de Missões do CELAM, que serviu como preparativo para a Conferência de Medellín e foi realizado em Melgar (Colômbia). Nesse período a igreja mexicana ainda mantinha poucos contatos com representantes do clero de outras regiões latinoamericanas. Sendo assim, acreditamos que o impacto causado pelo que Samuel Ruiz presenciou em Melgar pode ser considerado como uma ruptura em sua maneira de pensar a evangelização dos indígenas e, conseqüentemente, o marco que iniciou o processo de transformação da atuação da diocese de San Cristóbal.

Nas conclusões do Encontro de Melgar afirmou-se a necessidade dos diferentes grupos culturais serem integrados à vida nacional, o que "[...] se entiende con frecuencia, desgraciadamente, más como una destrucción de sus culturas, que como él reconocimiento de sus derechos a desarrollarse, a enriquecer el patrimonio cultural de la nación y a enriquecerse con él." (MELGAR apud SARMIENTO TUPAYUPANQUI, 1999, p. 26).

Como conseqüência teológica da pluralidade característica da América Latina, as conclusões alcançadas em Melgar orientam para uma valorização da história cultural (línguas, costumes, instituições, valores e aspirações) de cada povo e da diversidade cultural na Igreja católica "[...] que se manifiesta y se expresa en la fe y el lenguaje cultural de las Iglesias locales [...]" (SARMIENTO TUPAYUPANQUI, 1999, p. 26).

\footnotetext{
hibridizados com as culturas de origem européia). Isto torna inapropriada a designação de "indígena" a uma teologia de origem católica, mesmo que "encarnada" em uma cultura indígena. Nesta Dissertação optamos por manter o emprego da denominação Teologia Indígena em razão dos outros termos não parecerem resolver suficientemente o problema referido e deste termo ainda ser o que possui uso mais corrente. Para conhecer mais sobre a Teologia Indígena sugere-se consultar, entre outros, o sítio do Conselho Indigenista Missionário - CIMI (http:// www.cimi.org.br/), onde é possível encontrar diversas resoluções, documentos finais de encontros e artigos que tratam do tema em questão.

18 Em razão da necessidade de não exceder o espaço reservado a este artigo, não apresentaremos detalhes acerca dessas Conferências e Encontros. Para conhecer mais sobre o assunto sugere-se conferir: Sarmiento Tupayupanqui ( 1999).
} 
Em outra parte das conclusões, afirma-se que a promoção humana por parte da Igreja não implica necessariamente na criação de instituições próprias:

[...] sino una acción que ayude a las comunidades indígenas a asumir su propia responsabilidad, evitando todo paternalismo [...]

Es fundamental que la presencia misionera de la Iglesia respete las diversas culturas y las ayude a evolucionar de acuerdo con sus características propias, abiertas al intercambio con otros grupos culturales. Se reconoce que las culturas autóctonas presentan características marcadamente sacrales, y pues están abocadas a recibir el impacto de la civilización técnica y de la secularización, hay que prepararlas para que dicho impacto no las desintegre. (SARMIENTO TUPAYUPANQUI, 1999, p. 27).

\section{Além disso, para essa "promoção humana" que os documentos se referem} constantemente, enfatiza-se o necessário acompanhamento de estudos apoiados nas ciências sociais, sobretudo antropológicos e lingüísticos.

O pensamento de Samuel Ruiz foi profundamente marcado pelas conclusões do Encontro de Melgar. ${ }^{19}$ Acerca do impacto do Encontro é oportuno conferir as palavras do próprio bispo de San Cristóbal:

[...] el antropólogo Gerardo Reichel-Dolmatoff 20 [...] Me hizo ver que la evangelización tal como se estaba llevando a cabo en el continente, era simple y llanamente una destrucción de culturas y una acción dominadora.

[...] Dolmattoff hizo ver que las culturas indígenas [...] eran el caminar milenario de pueblos para llegar a configurar una forma de pensar, de ser, de articularse dentro de la sociedad, y que la repercusión de un cambio, de una modificación hecha desde el exterior traía una reacción en cadena, destructiva [...]

Me dejo aturdido, confundido, el planteamiento aquel [...]

Me paré y le pregunté al antropólogo: 'En las culturas indígenas que usted conoce [...] ¿La religión es algo secundario o algo fundamental?’. Dolmatoff me respondió: 'En todas las culturas indígenas que yo

19 Uma análise mais aprofundada das características predominantes no pensamento sócio-teológico do bispo Samuel Ruiz após o Encontro de Melgar é também parte da Dissertação que dá origem a este texto e será objeto de outro artigo.

20 Gerardo Reichel-Dolmatoff nasceu em 1912 em Salzburgo, na Áustria, e faleceu em 1994. Às vésperas da Segunda Guerra Mundial emigrou para a Colômbia, onde iniciou suas pesquisas nas áreas da Antropologia e Arqueologia. Tornou-se cidadão colombiano em 1942. Foi um dos pioneiros e mais importantes pesquisadores no campo antropológico colombiano, tendo como especialidade o estudo de culturas originárias de regiões de florestas tropicais em toda a Colômbia e outras regiões das América do Sul, a partir de investigações holísticas, onde buscava adotar uma política consciente de observação participante, visando compreender as visões de mundo das populações em análise. Em 1967 já era um pesquisador conhecido e respeitado em seu campo de atuação, tendo estabelecido um quadro de base cronológica para a área Etnológica da Colômbia - que é utilizado até hoje; criado uma equipe de pesquisadores concentrados em Arqueologia Colombiana; dirigido um instituto Etnológico; publicados estudos clássicos na área étnico-histórica; e criado o primeiro departamento de Antropologia da Colômbia, na Universidad de Los Andes. 
conozco, la religión es un elemento definitivamente aglutinante de todos los factores culturales'.

[...] Me quedaba una incógnita terrible: 'Entonces ¿qué cosa era evangelizar? ¿Era destruir culturas? [...] ¿Por qué permitió Dios la existencia de tantas culturas? [...] (RUIZ apud FAZIO, 1994, p. 86-87).

Uma indicação de onde poderiam surgir as respostas para essas e outras perguntas que atormentavam Dom Samuel Ruiz adveio na palestra do dia seguinte em Melgar, onde Gustavo Gutiérrez apresentou um resumo da postura missionária presente em documentos (Ad Gentes) do Concílio Vaticano II.

O Ad Gentes é um documento onde predominam características inovadoras, relativamente pluralistas, por outro lado é um documento "aberto", facilmente passível a interpretações contrárias. É muito provável e compreensível que o resumo apresentado por Gustavo Gutiérrez - e conseqüentemente a chave de leitura a partir de então empregada por Samuel Ruiz - relegasse as passagens mais tradicionais e focasse nos apontamentos mais "progressistas" do Ad Gentes. Segue abaixo um destes apontamentos:

[...] Cristo, por Sua encarnação se ligou as condições sociais e culturais dos homens com quem conviveu, assim deve a Igreja inserir-se em todas [...] sociedades [...]

[...] Reconheçam-se como membros do corpo social em que vivem, e tomem parte na vida cultural e social através das várias relações e ocupações da vida humana. Familiarizem-se com suas tradições nacionais e religiosas. Com alegria e respeito descubram as sementes do Verbo aí ocultas. (CONCÍLIO VATICANO II, 2009).

A partir do encontro em Melgar, Samuel Ruiz alinhou-se a esse pequeno grupo ligado ao Departamento de Missões do CELAM e retomou a leitura dos documentos do Concílio, sobretudo o Ad Gentes, reconhecendo que não havia assimilado questões importantes, assim iniciando a transformação de sua missão evangelizadora na diocese de San Cristóbal, partindo da premissa de que, uma vez que Deus quer a salvação de todos os homens, então Ele, de algum modo, está presente em todo e qualquer grupo humano e, desta forma, ao invés de anunciar Cristo aos indígenas, o papel do evangelizador deve ser o de descobrir Deus encarnado na história e, conseqüentemente, na cultura daquelas comunidades. 
Em virtude de uma série de acontecimentos fortuitos ${ }^{21}$ Samuel Ruiz acabou por ser um dos sete bispos de toda América Latina convidados a discursar em Medellín, onde se posicionou ao lado do setor mais radical do clero latino-americano. A preparação para sua conferência levou Dom Samuel Ruiz a entrar em contato e aderir a reflexões teológicas construídas a partir do contato com a teoria da dependência. Nas palavras do próprio bispo:

\begin{abstract}
Creo que lo que hace Medellín es descubrir, con la sociología, la situación de marginación y dependencia que vivían los pueblos de América Latina [...] Hasta entonces la Iglesia había estado unida a las élites económicas y de dominación; se partía de aquello concepto de que los desarrollados debían ayudar los subdesarrollados. Pero en Medellín los obispos nos topamos con el analices sociológica de la época: el de la marginación. Y empezamos a descubrir que los marginados no están así porque quieren serlo, sino que es sistema el que los margina [...] Y que insertarlos en la sociedad en tales condiciones significaba no reconocer que el sistema margina. Mientras se insertaban diez o quince al sistema mediante un proceso de ayuda, el sistema ya había fabricado mil marginados [...] (RUIZ apud FAZIO, 1994, p. 94).
\end{abstract}

Em Medellín a questão indígena foi relegada, aparecendo somente quatro vezes nos documentos finais. ${ }^{22}$ Mesmo que marginais em meio ao extenso volume apresentado pelos documentos finais da Conferência, essas orientações foram importantíssimas para o pequeno setor da Igreja católica cujas principais preocupações relacionavam-se com a realidade indígena latino-americana. Por outro lado, entendemos que o aprendizado mais contundente proporcionado por Medellín para o pensamente de Samuel Ruiz foi o da percepção de que a situação de miséria encontrada nas comunidades indígenas não era produto de algo individual, mas sim um assunto estrutural, sistêmico. Atinou para necessidade da participação da Igreja em ações sócio-políticas, mas acreditava que "[...] los indígenas máyenses no tenían conciencia de su historia [...]" (FAZIO, 1994, p. 107). Assim sendo, defendia que era necessário conscientizálos de sua própria história de opressão.

${ }^{21}$ Por haver estado em Melgar, Samuel Ruiz foi convidado para outro encontro preparativo para a Conferência de Medellín. Neste novo encontro, o arcebispo Marcos MacGrath, do Panamá, que era o vice-presidente do CELAM, lhe fez um resumo das intervenções e pediu que as transcrevesse. Posteriormente este texto foi atribuído a Samuel Ruiz, ignorando que as indicações eram do arcebispo do Panamá. Foi em conseqüência desde mal entendido que o bispo de Chiapas foi convidado a discursar na Conferência de Medellín.

22 Novamente em decorrência da limitação de espaço imposta a este artigo, não entramos em detalhes acerca dessas quatro indicações referentes à questão indígena que constam nos documentos finais da Conferência de Medellín. 
Entretanto, isto não significou que o bispo simplesmente abandonou sua bagagem familiar e formação teológica. Apesar de haver incorporado alguns de seus elementos característicos, nunca defendeu o marxismo. Ademais, a própria realidade (indígena) com a qual lidava em Chiapas dificultava a adoção integral de explicações que reduzissem a complexidade do real aos aspectos econômicoestruturais, relegando outros, como as questões culturais.

Desta forma, o tema dominante no pensamento de Dom Samuel Ruiz passou a ser a encarnação da teologia nas culturas indígenas, entretanto sem esquecer-se da necessidade de combater a opressão às comunidades, tanto a opressão material como a cultural, na qual a própria Igreja possuía um papel de destaque ao impor, através da evangelização, um sistema cultural externo.

Portanto, os preparativos (sobretudo Melgar) e a própria Conferência de Medellín marcaram um ruptura em direção ao que posteriormente passou a ser conhecido como Teologia Indígena, isto é, em linhas gerais, o entrelaçamento entre, por um lado, o incentivo à luta por autolibertação e transformações sócioeconômicas e, por outro lado, as preocupações de cunho étnico-teológico que levaram a busca pela formação de Igrejas autóctones, assim levando à transformação, para além da relação teológica, da atuação paternalista, indigenista e desenvolvimentista da diocese de San Cristóbal para com as comunidades indígenas. ${ }^{23}$

\section{Referências}

MESTRIES BENQUET, Francis. Antecedentes y motivos del movimiento indígena zapatista. Estudios Agrarios, México, n. 16, p. 117-147, 2001.

CONCÍLIO VATICANO II. Ad Gentes: decreto "Ad Gentes" sobre a atividade missionária da Igreja. 2010. Disponível em: <http:/ / www.cleofas.com.br/ virtual/impressao.php?doc=CONCILIO \&id+con1043>. Acesso em: 15 out. 2009.

COUTROT, Aline. Religião e política. In: RÉMOND, René. Por uma história política. 2. ed. Rio deJ aneiro: FGV, 2003. p. 331-364.

\footnotetext{
${ }^{23}$ Contudo, os efeitos dessa guinada do pensamento político-teológico do bispo de Chiapas não foram - tampouco poderiam ser - imediatos. As transformações possibilitadas foram ocorrendo de maneira paulatina. Este processo de transformações ocorridas a partir da diocese de San Cristobál após o Encontro de Melgar será tratado em outro artigo - também resultante de uma síntese de reflexões que constam na Dissertação que deu origem a este texto.
} 
DUSSEL, Enrique. Historia de la Iglesia en América Latina: medio milenio de coloniaje y liberación (1492-1992). 6. ed. Madrid: Mundo Negro, 1992.

FAZIO, Carlos. Samuel Ruiz: el caminante. México: Espasa Calpe, 1994.

FIGUEIREDO, Guilherme Gitahy de. A guerra é o espetáculo: origens e transformações da estratégia do EZLN. 2003. Dissertação (Mestrado em Ciencia Politica) - Universidade Estadual de Campinas, Campinas.

LIBÂNIO, J oão Batista. Panorama da teologia da América Latina nos últimos anos. Disponível em: <http:// www.servicioskoinonia.org/ relat/229.htm>. Acesso em: 28 ago. 2008.

LÖWY, Michel. A guerra dos deuses: religião e política na América Latina. Petrópolis: Vozes, 2000.

MESTRIES BENQUET, Francis. Antecedentes y motivos del movimiento indígena zapatista. Estudios Agrarios, México, n. 16, p. 117-147, 2001.

MEYER, J ean. Estado y sociedad con Calles. México: El Colegio de México, 1981.

MEYER, J ean. Historia de los cristianos en América Latina: siglos XX y XIX. México: Vuelta, 1989.

MURO, Víctor Gabriel. Grupos cristianos y movimientos campesinos en México. Revista Mexicana de Sociología, México, n. 2, p. 165-175, 1994.

NAVARRETE, Federico. Las relaciones inter-étnicas en México. México: UNAM, 2004.

OLIVEROS MAQUEO, Roberto. Historia Breve de la Teología de la Liberación (1962-1990). In: ELLACURÍA, Ignácio ; SOBRINO, J on. (Org.). Mysterium liberationis: conceptos fundamentales de la Teología de la Liberación. Madrid: Trotta, 1990. v. 1, p. 17-50.

PAULO VI, Papa. Carta encíclica: Populorum Progressio: de sua santidade o Papa Paulo VI sobre o desenvolvimento dos povos. Disponível em: $<$ http:// www.vatican.va/ holy_father/paul_vi/ encyclicals/documents/ hf_pvi_enc_26031967_populorum_po.html>._Acesso em: 1 out. 2009.

RADO, Maria Ligia Coelho. A formação das nações latino-americanas. 2. ed. São Paulo: Atual, 1986.

SAINT-PIERRE, Héctor Luis. Don Samuel Ruiz, el obispo guerrillero de Chipas y la declaración de guerra de la selva Lacandona. Revista de Ciencias Sociales, Buenos Aires, n. 12, p. 63-84, 2001. 
SARMIENTO TUPAYUPANQUI, Nicanor. La prehistoria de la teología india. In: . Teología india en la iglesia latinoamericana. 1999. Tese (Doutorado)

- Universidad Católica de Bolivia, Santa Cruz.

TORRES-LONDOÑO, Fernando. 1955-1979 três Conferências Gerais do Celam e uma Igreja ante o desafio de transformação na América Latina. Religião \& Cultura, São Paulo, v. 4, n. 12, p. 11-29, 2007.

VILLORO, Luis. O futuro dos povos indígenas/I. In: BUENROSTROY ARELLANO, Alejandro; OLIVEIRA, Ariovaldo Umbelino de (Org.). Chiapas: construindo a esperança. São Paulo: Paz e Terra, 2002. p. 173-176.

VOS, J an De. Una tierra para sembrar suemos: historia reciente de la Selva Lacandona, 1950-2000. México: Fondo de Cultura Económica, 2002.

Colaboração recebida em 03/ 06/2010 e aprovada em 13/03/2011. 